\title{
Flooding Diagram for Multi-phase Flow in a Moving Bed
}

\author{
X. F. DONG, ${ }^{1)}$ T. PHAM, ${ }^{1)}$ A. B. YU ${ }^{11}$ and P. ZULLI' \\ 1) Laboratory for Simulation and Modelling of Particulate Systems, School of Materials Science and Engineering, The \\ University of New South Wales, Sydney, NSW 2052, Australia. E-mail: a.yu@unsw.edu.au. \\ 2) BlueScope Steel Research, P.O. Box 202, Port Kembla, NSW 2505, Australia.
}

(Received on October 3, 2008; accepted on November 21, 2008)

\begin{abstract}
Flooding phenomena typically represent liquid overflow and unstable flow behaviour in a gas-liquid counter-current flow within a fixed bed. Understanding the flooding phenomena in a multi-phase flow system is important to process design and optimization. This paper presents a study of the flooding phenomena in two systems: gas-liquid flow and gas-liquid-powder flow in moving beds. Experiments are conducted in a one-dimensional column involving upward gas and powder flow and downward solids and liquid flow. Based on the experimental findings, a correlation is formulated which considers the effects of particle moving and the presence of powder phase. The correlation can be used to generate flooding diagrams to depict flooding and non-flooding regions for multi-phase flow in a moving bed.
\end{abstract}

KEY WORDS: flooding diagram; multi-phase flow; packed beds.

\section{Introduction}

Packed bed reactors with a counter-current gas-liquid flow are widely used in chemical, metallurgical, petrochemical and mineral industries. In such a reactor, liquids flow downward and gases flow upward. Once gas flow rate reaches a critical value, liquids cannot flow downward, leading to holdup and/or overflow. This phenomenon is usually referred to as "flooding". ${ }^{1)}$ Flooding can cause unstable operations and a significantly increased pressure drop. Therefore, understanding and controlling flooding phenomena are of considerable practical importance.

Many studies have been conducted in the past focusing on gas-liquid flow in fixed beds with different packing materials. $^{2-13)}$ These studies have generated various correlations for the estimation of conditions leading to liquid flooding. The most important and generally accepted treatment is represented by the so-called SLE (Sherwood-LevaEckert) flooding diagram. ${ }^{13}$ This diagram was originated by Sherwood et al., ${ }^{2}$ who summarized the early experimental data in terms of the flooding factor and fluid ratio. Later, it was extended by Leva ${ }^{6}$ who introduced pressure drop curves in the diagram in order to predict the increased pressure drop due to the presence of liquid. Eckert ${ }^{8)}$ further modified the diagram to account for different packing structures. Other empirical or semi-empirical equations have been formulated for different engineering applications. ${ }^{3-5,7,9,10)}$

Flooding phenomena not only occur in gas-liquid flow in fixed beds, but also exist in more complicated flow conditions, e.g. multi-phase flow in moving beds. The ironmaking blast furnace (BF) is an example, where gas, liquid, powder and solid phases (four-fluids) coexist with upward gas-powder flow and downward liquid-solid flow. ${ }^{14,15)}$ In connection with the gas-liquid flow in fixed beds, some studies have been carried out to understand the flooding phenomena in this system. ${ }^{16-19)}$ However, there are various limitations associated with these previous studies. For example, they were focused on fixed beds rather than moving beds, and the effect of powder phase was not considered. The latter becomes important because of the wide application of pulverized coal injection in modern BF ironmaking. ${ }^{20,21)}$ Therefore, this paper aims to study and quantify the flooding phenomena in the following systems: gasliquid flow in fixed/moving beds and gas-powder-liquid flow in a moving bed. In particular, it focuses on the formulation of new correlations to describe the flooding diagram in these systems.

\section{Experimental Work}

\subsection{Method and Materials}

As shown in Fig. 1, the experimental rig used is an acrylic packed column with an internal diameter of $57 \mathrm{~mm}$ and a height of $800 \mathrm{~mm}$. The solid movement is generated by continuously removing particles at the bottom of the bed and transporting them to a solid collector via a screw feeder. The solid particles are continuously introduced at the top via a hopper to compensate for those removed at the bottom. Liquid is fed into the top of the column through a single inlet point via a peristaltic pump, and liquid draining from the outlet is collected from the bottom of the bed. Powder is fed into a gas stream from a powder screw feeder and entrained by gas, flows into the bed through a gas-powder distributor at the bottom of the column. Gas exiting from the top of the column passes through a cyclone where the powder is separated, collected and weighed by a digital balance and the off-gas is vented to the atmosphere. The 


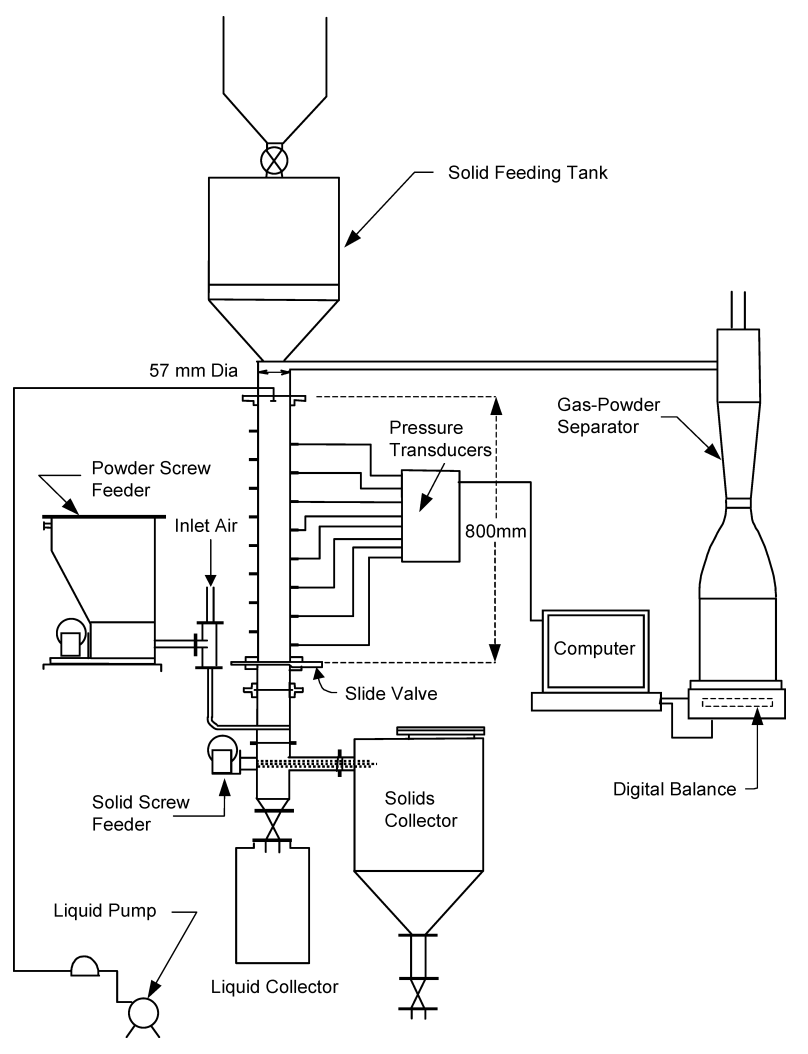

Fig. 1. Schematic diagram of the experimental apparatus used.

gas flowrate is controlled by a rotameter. The pressure drop across the bed is measured by pressure transducers attached to the column at intervals of $100 \mathrm{~mm}$. Both the pressure drop profile and powder outlet mass are recorded continuously by a computer.

For simplicity, the present study focuses on the most basic but representative laboratory system which involves the use of simple materials such as air, water, glass beads and glass powder to simulate gas, liquid, solid and powder phases in a BF. The experiments are conducted under flow conditions similar to those found in the belly or lower shaft of the BF. The diameter of glass beads used in this study $(3 \mathrm{~mm})$ is much smaller than the internal diameter of the packed column $(57 \mathrm{~mm})$ and thus guarantees a uniform motion of solid particles with negligible wall effect. ${ }^{22)}$ Glass powder used is in the A/B-type Geldart classification ${ }^{23)}$ where powder particles are not subjected to significant cohesive forces and behave as discrete entities. Table 1 lists the physical properties of these materials, together with the flow conditions for the experiments. As listed in Table 1, the dimensionless numbers describing the fluid flows in the experiments and $\mathrm{BF}$ are comparable.

In a typical four-fluid flow experiment, gas is initially introduced into the packed bed, followed by the extraction of solid particles at the bottom to generate a moving bed. The injection of liquid on the top of the bed is followed by the introduction of powder into the gas stream. The introduction of each fluid into the bed is made when the previous system has reached a steady state. Similar procedures have also been used for gas-liquid flow in a moving bed without considering powder phase and for gas-liquid flow in a fixed bed. In the experiments, the steady state is justified mainly based on the stable pressure drop across the bed and mass
Table 1. Comparison of conditions in the present study and in a BF.

\begin{tabular}{|c|c|c|c|}
\hline \multirow[b]{2}{*}{ Variables } & \multirow{2}{*}{$\begin{array}{c}\text { Present Study } \\
\left(25^{\circ}\right)\end{array}$} & \multicolumn{2}{|c|}{ Blast furnace $\left(1600^{\circ}\right)$} \\
\hline & & Metal & Slag \\
\hline Particle diameter, $\mathrm{m}$ & $3.0 \times 10^{-3}$ & \multicolumn{2}{|c|}{$\sim 25 \times 10^{-3}$} \\
\hline Powder diameter, $\mathrm{m}$ & $(7.4-14.9) \times 10^{-5}$ & \multicolumn{2}{|c|}{$(7.4-300.0) \times 10^{-5}$} \\
\hline Bed diameter, $\mathrm{m}$ & 0.057 & \multicolumn{2}{|c|}{10} \\
\hline Bed voidage, $\mathrm{m}^{3} \cdot \mathrm{m}^{-3}$ & 0.42 & \multicolumn{2}{|c|}{$0.3-0.4$} \\
\hline Gas density, $\mathrm{kg} \cdot \mathrm{m}^{-3}$ & 1.177 & \multicolumn{2}{|c|}{0.2} \\
\hline Particle density, $\mathrm{kg} \cdot \mathrm{m}^{-3}$ & 2500 & \multicolumn{2}{|c|}{550} \\
\hline Powder density, $\mathrm{kg} \cdot \mathrm{m}^{-3}$ & 2500 & \multicolumn{2}{|c|}{300} \\
\hline Liquid density, $\mathrm{kg} \cdot \mathrm{m}^{-3}$ & 1000 & 6600 & 2600 \\
\hline Gas viscosity, $\mathrm{kg} \cdot \mathrm{m}^{-1} \cdot \mathrm{s}^{-1}$ & $1.86 \times 10^{-5}$ & \multicolumn{2}{|c|}{$6.0 \times 10^{-5}$} \\
\hline Liquid viscosity, $\mathrm{kg} \cdot \mathrm{m}^{-1} \cdot \mathrm{s}^{-1}$ & 0.001 & 0.005 & 0.3 \\
\hline Liquid surface tension, $\mathrm{N} \cdot \mathrm{m}^{-1}$ & 0.073 & 1.19 & 0.3 \\
\hline Gas superficial velocity, $\mathrm{m} \cdot \mathrm{s}^{-1}$ & $0.12-0.817$ & \multicolumn{2}{|c|}{$1-2$} \\
\hline Solid superficial velocity, $\mathrm{m} \cdot \mathrm{s}^{-1}$ & $(0.0-7.4) \times 10^{-4}$ & \multicolumn{2}{|c|}{$(1.5-2.0) \times 10^{-3}$} \\
\hline Liquid superficial velocity, $\mathrm{m} \cdot \mathrm{s}^{-1}$ & $(0.0-1.3) \times 10^{-3}$ & \multicolumn{2}{|c|}{$(0.9-1.5) \times 10^{-4}$} \\
\hline Powder mass flux, $\mathrm{kg} \cdot \mathrm{m}^{-2} \mathrm{~s}^{-1}$ & $0.0-0.3$ & \multicolumn{2}{|c|}{$\sim 0.1$} \\
\hline $\begin{array}{l}\text { Gas Reynolds number } \\
R e_{g}=\rho_{g} U_{g} d_{s} / \mu_{g}\end{array}$ & $22-155$ & \multicolumn{2}{|c|}{$83-167$} \\
\hline $\begin{array}{l}\text { Liquid Reynolds number } \\
R e_{l}=\rho_{l} U_{l} d_{s} / \mu_{l}\end{array}$ & $0.0-4.0$ & $2.97-4.95$ & $\begin{array}{l}0.0195- \\
0.0325\end{array}$ \\
\hline $\begin{array}{l}\text { Froude number } \\
F r_{s}=U_{s} /\left(d_{s} g\right)^{0.5}\end{array}$ & $(0.0-4.3) \times 10^{-3}$ & \multicolumn{2}{|c|}{$(3-4) \times 10^{-3}$} \\
\hline
\end{tabular}

balance of fluid flow at the inlet and outlet. Moreover, according to the measurements made, the pressure drop is linearly distributed over the column. This demonstrates a uniform bed permeability along the longitudinal direction of the packed bed. If unsteady state flow occurs, the relationship between bed pressure drop and height is not linear. ${ }^{24)}$

\subsection{Key Experimental Findings}

During the experiment, flooding points are judged from the observation and pressure drop measurements. Two typical pressure drop variations are shown in Fig. 2, in which a steady-state four-fluid flow without flooding gives a constant pressure drop (Fig. 2(a)), whereas an unsteady-state flow is characterised by a continuously increasing pressure drop, leading to a flooding bed (Fig. 2(b)).

In the range of experimental conditions summarised in Table 1, the effects of parameters such as the superficial gas velocity, superficial liquid velocity and solid velocity on the relative size and locations of the flooding and non-flooding regions in the four-fluid system are shown in Fig. 3. Figure 3(a) plots the flooding points as a function of solid velocity and powder mass flux for different liquid velocities. The non-flooding region expands with the decrease of liquid velocity under a constant gas velocity. This is mainly because, with decreasing liquid velocity, the interaction between liquid and powder phases gets weak and the steady state multiphase flow becomes more achievable. Figure 3(b) shows that for fixed gas and solid velocities, liquid velocity causing flooding decreases with an increase in powder mass flux due to the reduction in bed porosity and the interaction between fine powder and liquid. In particular, as shown in Fig. 3(c), the maximum allowable powder mass flux can increase to a maximum and then decrease with increasing gas velocity. However, when the gas velocity is lower than the minimum transport velocity $u_{\mathrm{t}}$, blockage may occur. The 


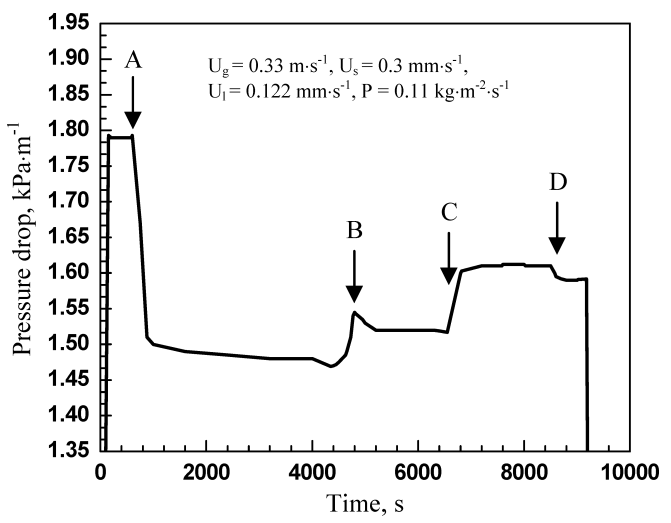

(a)

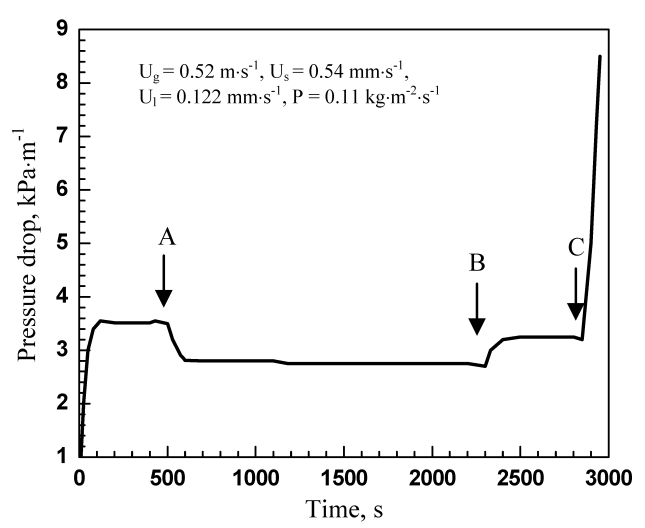

(b)

Fig. 2. Measured pressure drop for a steady-state (a) and unsteady-state (b) four fluid flow: (A) starting solid flow; (B) starting liquid injection; (C) starting powder injection; and (D) stopping liquid, powder and solid flows.

minimum transport velocity here refers to as the critical gas velocity lower than which powder cannot be entrained by gas, and instead accumulates in the bottom of a bed resulting in blockage and hanging as observed by Shibata et al. ${ }^{25)}$ and Yamaoka et al. ${ }^{26)}$ Pham et al. ${ }^{27)}$ have discussed the experimental results in more detail elsewhere. The results will be further discussed in the following section focussing on correlation analysis.

\section{Formulation of Empirical Equations}

It is useful to formulate empirical equations to predict phase diagrams under different conditions. For this purpose, the flooding data obtained from the physical experiments have been analysed in order to validate the experimental techniques and lay out a sound base for the analysis of multi-phase system. In this section, attention is first given to simple gas-liquid flow in a fixed bed. Then, the effect of the descent of solid particles is considered. Finally, a general correlation is formulated for gas-powder-liquid flow in a moving bed.

\subsection{Gas-Liquid Flow in a Fixed Bed}

Flooding analysis of gas-liquid flow in fixed beds is firstly conducted. The original Sherwood diagram ${ }^{2)}$ is made based on the flooding data in packed beds of dumped and stacked rings. However, significant difference can be found from packing to packing. ${ }^{11)}$ This is also one of the reasons

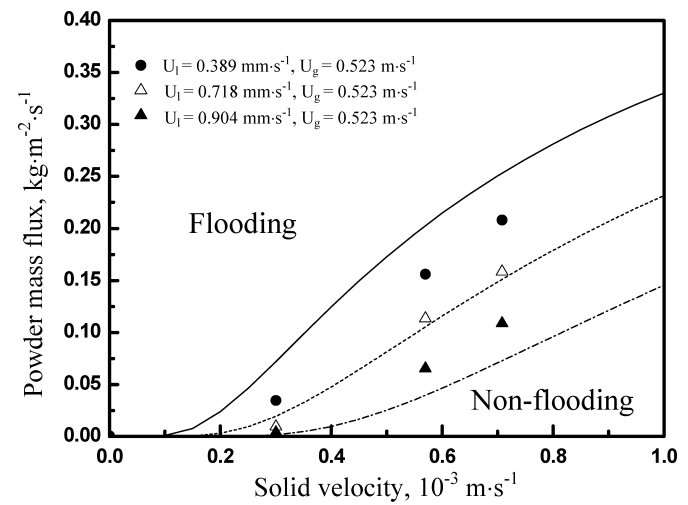

(a)

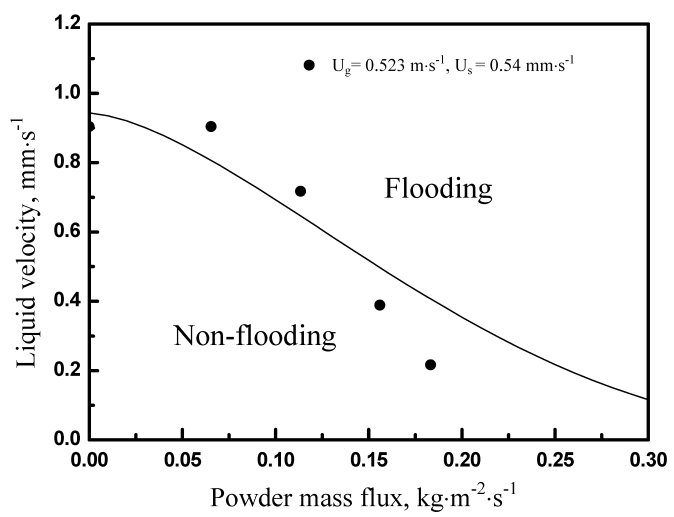

(b)

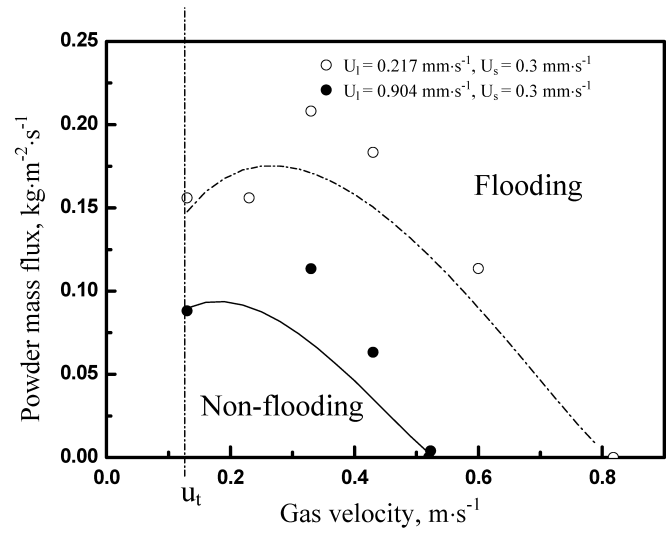

(c)

Fig. 3. Flooding and non-flooding regimes as a function of gas, liquid, solid velocity and powder mass flux: points, measured; lines, calculated by Eqn. (5). Note $u_{\mathrm{t}}=0.13 \mathrm{~m} \cdot \mathrm{s}^{-1}$.

why there is not a general diagram for all engineering applications. Therefore, current flooding data for gas-liquid flow in fixed beds are mainly compared to the data collected from the previous studies in the metallurgical field, including those from Elliott et al. ${ }^{16)}$ for low liquid flow rates, Szekely and Mendrykowski ${ }^{18)}$ for heavy liquid, and Fukutake and Rajakumar ${ }^{19)}$ for wetting and non-wetting systems.

In these previous studies, the experimental conditions provide similarity with the BF operational conditions even though most of them are for fixed beds packed with spherical particles. This allows the current collected data to be compared with the literature data. The flooding diagram are all established in terms of the so-called flooding factor $=$ 


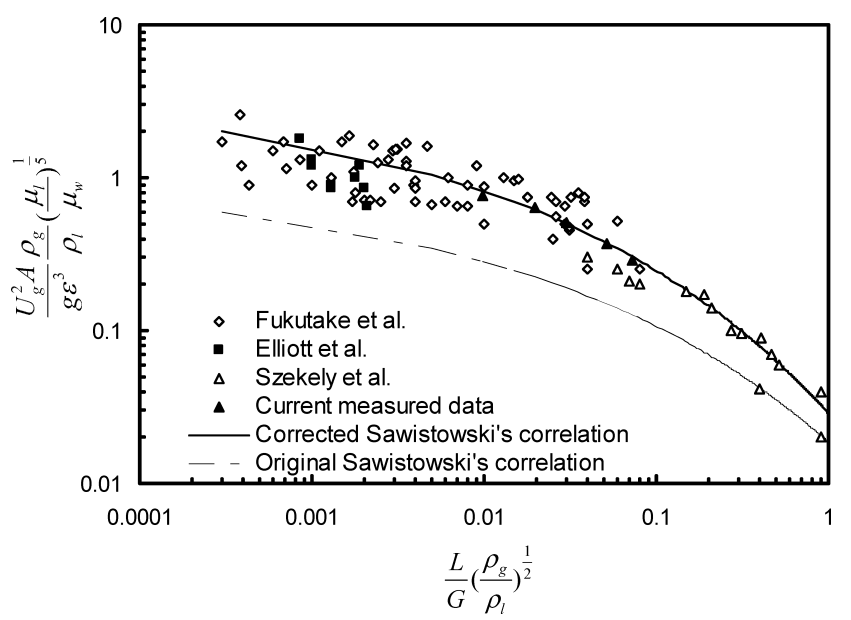

Fig. 4. Comparison of the flooding data from different sources and those from the Sawistowski correlation ${ }^{7}$.

$\left(U_{\mathrm{g}}^{2} A / g \varepsilon^{3}\right)\left(\rho_{\mathrm{g}} / \rho_{1}\right)\left(\mu_{\mathrm{l}} / \mu_{\mathrm{w}}\right)^{1 / 5}$ and fluid ratio $\left.=(L / G)\left(\rho_{\mathrm{g}} / \rho_{1}\right)^{1 / 2} \cdot \cdot^{28}\right)$ As shown in Fig. 4, the current measured data are consistent with those from the previous investigations, which validates the present flooding definition and the method for data processing. In order to establish corresponding correlations, Sawistowski's correlation ${ }^{7)}$ is used to fit the experimental data because this correlation provides a linear relation between the flooding factor and fluid ratio through a simple transformation. This correlation satisfactorily describes the earlier published data, ${ }^{2,28)}$ as given by

$$
\log \frac{U_{\mathrm{g}}^{2} A}{g \varepsilon^{3}} \frac{\rho_{\mathrm{g}}}{\rho_{\mathrm{l}}}\left(\frac{\mu_{1}}{\mu_{\mathrm{w}}}\right)^{1 / 5}=b_{1}\left(\frac{L}{G}\right)^{1 / 4}\left(\frac{\rho_{\mathrm{g}}}{\rho_{\mathrm{l}}}\right)^{1 / 8}
$$

where $b_{1}=-1.73$ for packed beds of raschig rings. However, when Eq. (1) is used to describe the data collected in packed beds with spherical particles for the present analysis, it underestimates the flooding factor consistently as shown in Fig. 4. The underlying reason for this is related to the different packing structures and flow conditions for packed beds with raschig rings and spherical particles. The void fraction for the packing of raschig rings is high compared with that of spherical particles and the interfacial contact between solid particles and liquid droplets is quite different for these systems. Therefore, it is necessary to modify this equation for the current flow system. The modified equation can be obtained by regression analysis, giving

$$
\log \frac{U_{\mathrm{g}}^{2} A}{g \varepsilon^{3}} \frac{\rho_{\mathrm{g}}}{\rho_{\mathrm{l}}}\left(\frac{\mu_{1}}{\mu_{\mathrm{w}}}\right)^{1 / 5}=b_{0}+b_{1}\left(\frac{L}{G}\right)^{1 / 4}\left(\frac{\rho_{\mathrm{g}}}{\rho_{1}}\right)^{1 / 8}
$$

where $b_{0}=0.587$ and $b_{1}=-2.127$. Figure 4 shows that Eq. (2) can match most of flooding points. More importantly, the correlation retains the simplicity of the original equation. The correlation analysis which follows will be carried out based on this modified empirical equation.

\subsection{Gas-Liquid Flow in a Moving Bed}

Previous flooding studies focussed on gas-liquid flows in fixed beds, without considering the effect of solid movement. In practice, moving beds are often utilised. For example, in a blast furnace, the burden (solids) flows under grav-

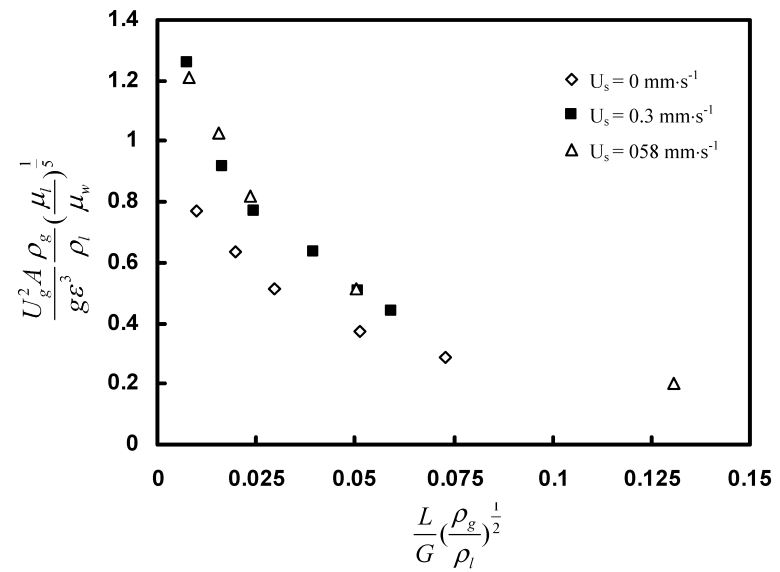

(a)

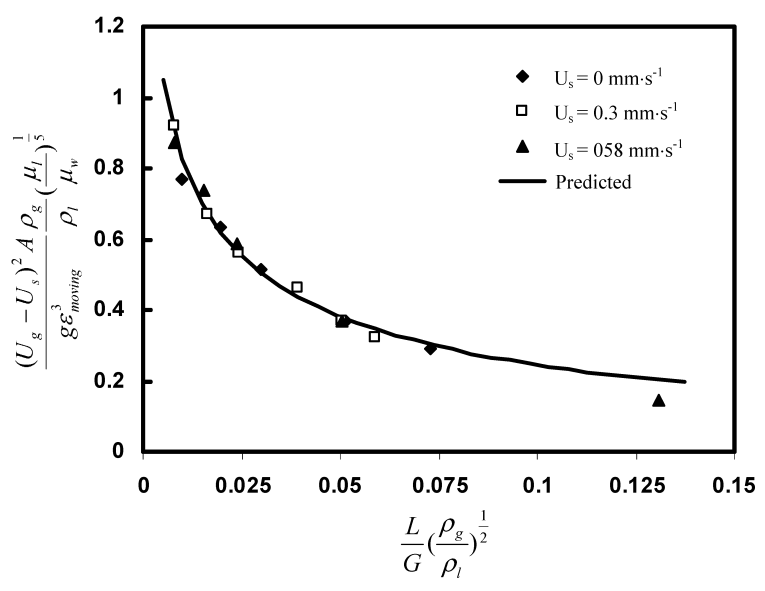

(b)

Fig. 5. Distribution of flooding data for gas-liquid flow in moving beds, without (a) and with (b) considering the effect of solid movement in the flooding factor.

ity, driven by the consumption of iron ore and coke. Therefore, in order to investigate this particular effect, flooding data have been obtained under different solid flowrates, as shown in Fig. 5(a). The results clearly indicate that solid movement affects the onset of flooding, i.e. the effect of a moving bed on flooding prediction cannot be ignored. Generally speaking, the effect results from two aspects: 1) the change of packing structure due to the solid movement; and 2) the variation of relative velocities between solids and other fluids. It has been observed that the porosity in a moving bed is a direct consequence of the changed packing structure, ${ }^{29,30)}$ which can be empirically described as a function of particle Froude number, given by

$$
\varepsilon_{\text {moving }}=\varepsilon_{\text {fixed }} \exp \left(0.13 \mathrm{Fr}_{\mathrm{s}}^{0.07}\right)
$$

where $\varepsilon_{\text {fixed }}(=0.42)$ represents the porosity of a fixed bed packed with spherical particles and the Froude number, $\mathrm{Fr}_{\mathrm{s}}$, includes key factors such as solid velocity and particle size. The effect of solid movement on porosity variation is not only due to expansion of the dense initial packed (fixed) bed, but also due to particle rearrangement while moving downward. This porosity variation and the relative velocity between gas and particles can be taken into account by modifying the related variables in the flooding factor and fluid ratio, which results in the following equation: 


$$
\log \frac{\left(U_{\mathrm{g}}-U_{\mathrm{s}}\right)^{2} A}{g \varepsilon_{\text {moving }}^{3}} \frac{\rho_{\mathrm{g}}}{\rho_{\mathrm{l}}}\left(\frac{\mu_{1}}{\mu_{\mathrm{w}}}\right)^{1 / 5}=b_{0}+b_{1}\left(\frac{L}{G}\right)^{1 / 4}\left(\frac{\rho_{\mathrm{g}}}{\rho_{1}}\right)^{1 / 8}
$$

Eq. (4) describes the flooding phenomena in moving beds quite well, as shown in Fig. 5(b). The coefficients $b_{0}$ and $b_{1}$ are same for Eqs. (2) and (4). Therefore, the modification necessary to describe the onset of flooding for a bed from fixed to moving state is rather straightforward.

\subsection{Gas-Liquid-Powder Flow in a Moving Bed}

The introduction of powder phase into the packed bed allows the study of four-fluid flow (gas, liquid, solid and powder phases). The flooding phenomena in this system differ from those in gas-liquid-solid three-fluid flow. The results in Fig. 3 summarized the measured flooding data in such a four-fluid system, showing that the flooding points significantly depend on powder flow rate. It is therefore necessary to further modify Eq. (4) to quantitatively describe flooding phenomena in this four-fluid flow system. To do so, a concept similar to the fluid ratio for gas and liquid phases is applied where an additional term, $P / G$, a fluid ratio relating to powder flow, is introduced. In the four-fluid flow system, the interaction between liquid and fine powder makes a significant contribution to flooding in the bed. However, at this stage, the mechanism of interaction between powder and liquid is unclear ${ }^{14,15)}$; it is hence difficult to judge the relationship between the newly introduced fluid ratios and other existing variables. Nonetheless, the flooding analysis can be still based on the assumption of linear relationship between fluid ratios and flooding factor. Regression analysis of the data in Fig. 3 gives

$$
\begin{aligned}
& \log \frac{\left(U_{\mathrm{g}}-U_{\mathrm{s}}\right)^{2} A}{g \varepsilon_{\text {moving }}^{3}} \frac{\rho_{\mathrm{g}}}{\rho_{\mathrm{l}}}\left(\frac{\mu_{1}}{\mu_{\mathrm{w}}}\right)^{1 / 5} \\
& \quad=b_{0}+b_{1}\left(\frac{L}{G}\right)^{1 / 4}\left(\frac{\rho_{\mathrm{g}}}{\rho_{1}}\right)^{1 / 8}+b_{2}\left(\frac{P}{G}\right)^{\frac{1}{2} \times 10^{3} \mathrm{Fr}_{\mathrm{s}}}
\end{aligned}
$$

where $b_{0}$ and $b_{1}$ are same as those in Eq. (4) and $b_{2}=-1.264$. Flooding points predicted by Eq. (5) are plotted in Fig. 3. There is a reasonable agreement between the calculated and measured results (approximately $\pm 20 \%$ ). Importantly, the key features are all there. For example, as the solid velocity approaches zero, the flow system becomes very unstable and essentially the non-flooding region cannot be achieved in the four-fluid flow system as shown in Fig. 3(a). In addition, the equation demonstrates that the flooding region decreases with increasing gas or liquid velocity and a maximum value for the maximum allowable powder mass flux with increasing gas velocity. Therefore, Eq. (5) can be used to estimate the flooding phenomena with confidence. Note that this equation is also applied to gas-liquid-solid system without any modification, demonstrating its flexibility and generality.

The effect of the powder phase on flooding can be illustrated in Fig. 6, where, for a given solid velocity, the measured data are plotted in a three-dimensional

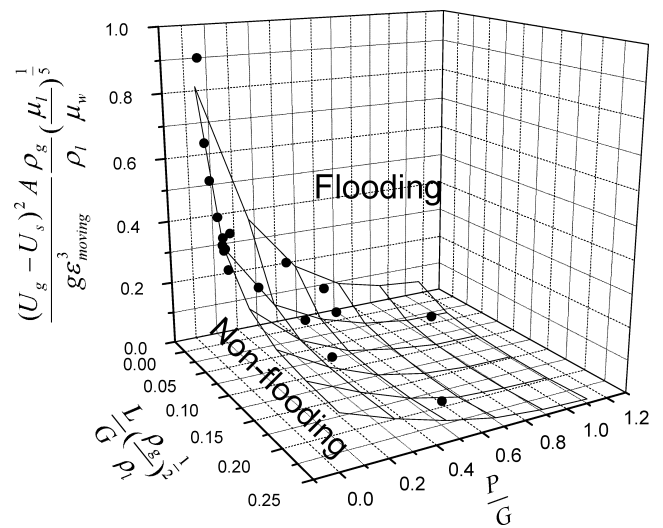

Fig. 6. Flooding diagram for gas-powder-liquid flow in a moving bed when solid velocity $=0.3 \mathrm{~mm} \cdot \mathrm{s}^{-1}$ (points: experimental).

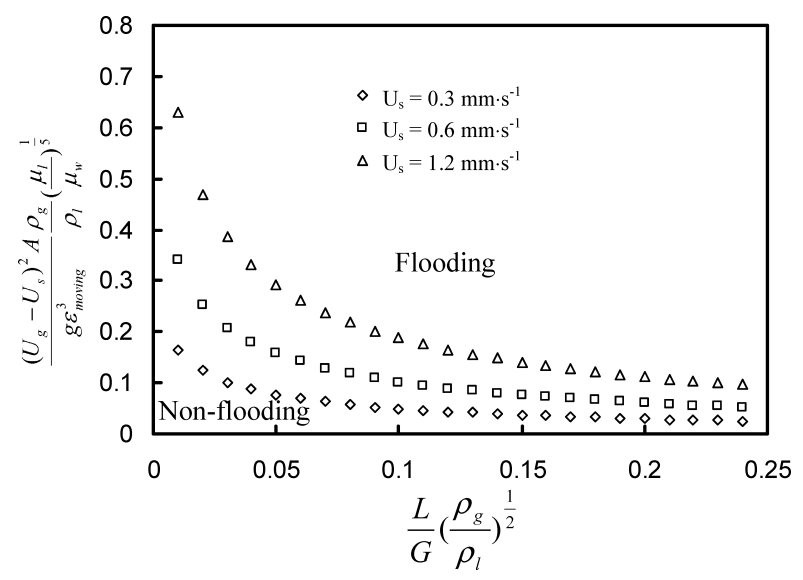

Fig. 7. Effect of solid velocity on flooding when fluid ratio $P / G=0.5$.

diagram in terms of three axis parameters: flooding factors $\left\{\left(U_{\mathrm{g}}-U_{\mathrm{s}}\right)^{2} A / g \varepsilon_{\text {moving }}^{3}\right\}\left(\rho_{\mathrm{g}} / \rho_{\mathrm{l}}\right)\left(\mu_{\mathrm{l}} / \mu_{\mathrm{w}}\right)^{1 / 5}$, fluid ratios $\mathrm{Fl}_{1}=(L / G)\left(\rho_{\mathrm{g}} / \rho_{1}\right)^{1 / 2}$, and $\mathrm{Fl}_{2}=P / G$. The predicted results generate a surface, above and below which represents the flooding and non-flooding regions respectively. It can be observed from Fig. 6 that the non-flooding region shrinks rapidly with increasing powder and/or liquid flowrate, i.e. flooding can occur quite easily in a four-fluid system. High powder or liquid flowrates should be avoided in order to achieve a stable operation. As expected, the two-dimensional Sherwood-type diagram can be regarded as a special case when the particle Froude number and powder fluid ratio are given in Fig. 6. As an example, Fig. 7 shows the corresponding diagram for constant solid flow rates and powder fluid ratio. Figure 7 also explicitly shows that the flooding is very sensitive to solid movement. With an increase of solid flowrate, the flooding region expands significantly, since high solid movement increases bed porosity and improves bed permeability.

\section{Conclusions}

Flooding phenomena in packed beds, where upward gaspowder flow and downward liquid-solid flows occur, have been analysed with special reference to the effects of gas, liquid, powder and solid flowrates in a gas-liquid-glass 
beads-glass powder system. The analysis is based on the stable three- and four-fluid flows realized in a one-dimensional packed bed. The following conclusions can be drawn from the present analysis:

- Flooding phenomena in gas-liquid-solid and gas-powder-liquid-solid flow system are very sensitive to solid movement and powder flowrate. The influence is mainly reflected by the variation of packing structure due to the solid movement, relative velocities between solid and other fluids, and powder-liquid interaction.

- A general empirical correlation has been formulated to predict the flooding diagram in three- or four-fluid flow systems, considering the porosity of a moving bed, the relative velocity between solid and other fluids, and a new fluid ratio related to powder flow.

- Three-dimensional flooding diagram can be established to identify flooding and non-flooding regions for multiphase flow in a moving bed. In general, the non-flooding region with stable four-fluid flow increases with the increase of solid flowrate and the decrease of gas, powder and/or liquid flowrate.

Finally, it should be pointed out that the current study is only concerned with an air-water-glass powder-glass beads system. While useful, the application of the resulting correlation to other flow systems composed of materials of different properties should be carefully examined. Moreover, although the flooding diagrams are mainly based on experimental measurements, theoretical model and analysis should be made in order to better understand the flooding phenomena and to formulate a more general correlation for general application. They will be carried out in our future studies.

\section{Acknowledgements}

The authors are grateful to the Australian Research Council and BlueScope Steel for the financial support of this work.

\section{Nomenclature}

$A$ : Surface area per packing volume, $\mathrm{m}^{2} \cdot \mathrm{m}^{-3}$; for the packing with spherical particle $A=6 \varepsilon_{\mathrm{s}} / d_{\mathrm{s}}$

$b_{i}$ : Empirical coefficients $(i=0,1,2)$

$d$ : Diameter, $\mathrm{m}$

$D^{*}$ : Hydrodynamic equivalent diameter, $D^{*}=$ $2 d_{\mathrm{s}}\left(1-\varepsilon_{\mathrm{s}}\right) / 3 \varepsilon_{\mathrm{s}}, \mathrm{m}$

Fr: Froude number: $\mathrm{Fr}_{\mathrm{s}}=U_{\mathrm{s}} /\left(d_{\mathrm{s}} g\right)^{0.5}$ for solid phase

g: Gravity acceleration, $\mathrm{m} \cdot \mathrm{s}^{-2}$

$G$ : Gas flow rate, $\mathrm{kg} \cdot \mathrm{m}^{-2} \cdot \mathrm{s}^{-1}$, the rate of mass flow across a unit empty area

$L$ : Liquid flow rate, $\mathrm{kg} \cdot \mathrm{m}^{-2} \cdot \mathrm{s}^{-1}$, the rate of mass flow across a unit empty area

$P$ : Powder flow rate, $\mathrm{kg} \cdot \mathrm{m}^{-2} \cdot \mathrm{s}^{-1}$, the rate of mass flow across a unit empty area

$\Delta P: \quad$ Pressure drop, $\mathrm{Pa}$

Re: Reynolds number: $\operatorname{Re}_{\mathrm{i}}=\rho_{i} U_{i} d_{\mathrm{s}} / \mu_{i}$ for $i=\mathrm{g}$ or 1

$U$ : $\quad$ Superficial velocity, $\mathrm{m} \cdot \mathrm{s}^{-1}$ $u_{t}: \quad$ Minimum transport velocity, $\mathrm{m} \cdot \mathrm{s}^{-1}$

Greek

$\varepsilon:$ Porosity

$\varepsilon_{s}$ : Solid volume fraction

$\rho$ : Density, $\mathrm{kg} \cdot \mathrm{m}^{-3}$

$\mu$ : Viscosity, $\mathrm{kg} \cdot \mathrm{m}^{-1} \cdot \mathrm{s}^{-1}$

Subscripts

f: Powder

fixed: Fixed bed

g: Gas

1: Liquid

moving: Moving bed

s: Solid

w: Water

\section{REFERENCES}

1) T. K. Sherwood: Absorption and Extraction, 2nd ed., McGraw-Hill Book Co., New York, (1952), 217.

2) T. K. Sherwood, G. H. Shipley and F. A. L. Holloway: Ind. Eng. Chem., 30 (1938), 765.

3) W. A. Bain and O. A. Hougen: Trans. Am. Inst. Chem. Eng., 40 (1944), 29.

4) J. W. Bertetti: Trans. Am. Inst. Chem. Eng., 38 (1942), 1023.

5) F. R. Dell and H. R. C. Pratt: J. Appl. Chem., 2 (1952), 429.

6) M. Leva: Chem. Eng. Prog. Symp. Ser., 50 (1954), 51.

7) H. Sawistowski: Chem. Eng. Sci., 6 (1957), 138.

8) J. S. Eckert: Chem. Eng. Prog., 66 (1970), 39.

9) A. E. Takahashi, Y. Akagi and K. Ueyama: J. Chem. Eng. (Japan), 12 (1979), 341.

10) J. Maćkowiak: Chem. Eng. Technol., 13 (1990), 184.

11) H. Z. Kister and D. R. Gill: Chem. Eng. Prog., 87 (1991), 32.

12) R. F. Strigle: Packed tower design and applications. Gulf Publ. Co., Houston, (1994), 1.

13) R. H. Perry and D. W. Green: Perry's Chemical Engineering's Handbook, 7th ed. McGraw-Hill, New York, (1997), 14-38.

14) J. Yagi: ISIJ Int., 33 (1993), 619.

15) X. F. Dong, A. B. Yu, J. Yagi and P. Zulli: ISIJ Int., 47 (1997), 1553.

16) J. F. Elliott, R. A. Buchanan and J. B. Wagstaff: J. Met., 194 (1952), 709.

17) N. Standish and J. B. Drinkwater: J. Met., 24 (1972), 43.

18) J. Szekely and J. Mendrykowski: Chem. Eng. Sci., 27, (1972), 959.

19) T. Fukutake and V. Rajakumar: Trans. Iron Steel Inst. Jpn., 22 (1982), 355.

20) J. Burgess: Aust. Coal J., 42 (1993), 29.

21) T. Sugiyama: Tetsu-to-Hagané, 82 (1996), 29.

22) R. P. Zou and A. B. Yu: Chem. Eng. Sci., 50 (1995), 1504.

23) D. Geldart: Powder Technol., 7 (1973), 285.

24) D. Pinson, T. Pham, A. B. Yu and P. Zulli: Steel Res. Int., 75 (2004), 106.

25) K. Shibata, M. Shimizu, S. Inaba, R. Takahashi and J. Yagi: ISIJ Int., 31 (1991), 434

26) H. Yamaoka: ISIJ Int., 31 (1991), 939.

27) T. Pham, D. Pinson, A. B. Yu and P. Zulli: Chem. Eng. Sci., 54 (1999), 5339.

28) W. E. Lobo, L. Friend, F. Hashmall and F. Zenz: Trans. Am. Inst. Chem. Eng., 41 (1945), 693.

29) T. Pham: Gas-powder-liquid three-fluid flow in moving particles for blast furnace modelling. $\mathrm{PhD}$ thesis, University of New South Wales, Sydney, Australia, (2001).

30) Z. Y. Zhou, H. P. Zhu, A. B. Yu, B. Wright, D. Pinson and P. Zulli: ISIJ Int., 45 (2005), 1828. 